Advances in Gene Technology: The Genome and Beyond -

Structural Biology for Medicine (Proceedings of the 2002 Miami

Nature Biotechnology Winter Symposium)

TheScientificWorld 2002, 2(S2), 136-137

ISSN 1532-2246; DOI 10.1100/TSW.2002.64

\title{
THE FOUR-STATE EQUILIBRIUM UNFOLDING OF A scFv ANTIBODY FRAGMENT
}

\author{
Idolka Pedroso, María P. Irún, Claudia Machicado, and Javier Sancho*
}

Departamento de Bioquímica y Biología Molecular y Celular. Facultad de Ciencias. Universidad de Zaragoza. 50009 Zaragoza (Spain)

*jsancho@posta.unizar.es

INTRODUCTION. Single chain Fv fragments $(\mathrm{scFv})$ are interesting alternatives to the use of whole antibody molecules[1]. We describe here an equilibrium intermediate of the thermal and urea unfolding that may compromise the stability of this class of molecules and constitute the main target for $\mathrm{scFv}$ stabilisation.

METHOD. The single-chain Fv antibody fragment against a hepatitis B surface antigen (antiHBsAg scFv) was a generous gift from the Centro de Ingeniería Genética y Biotecnología, la Habana, Cuba. The equilibrium unfolding and spectroscopic characterisation of the scFv was performed essentially as described for other proteins studied in our laboratory[2].

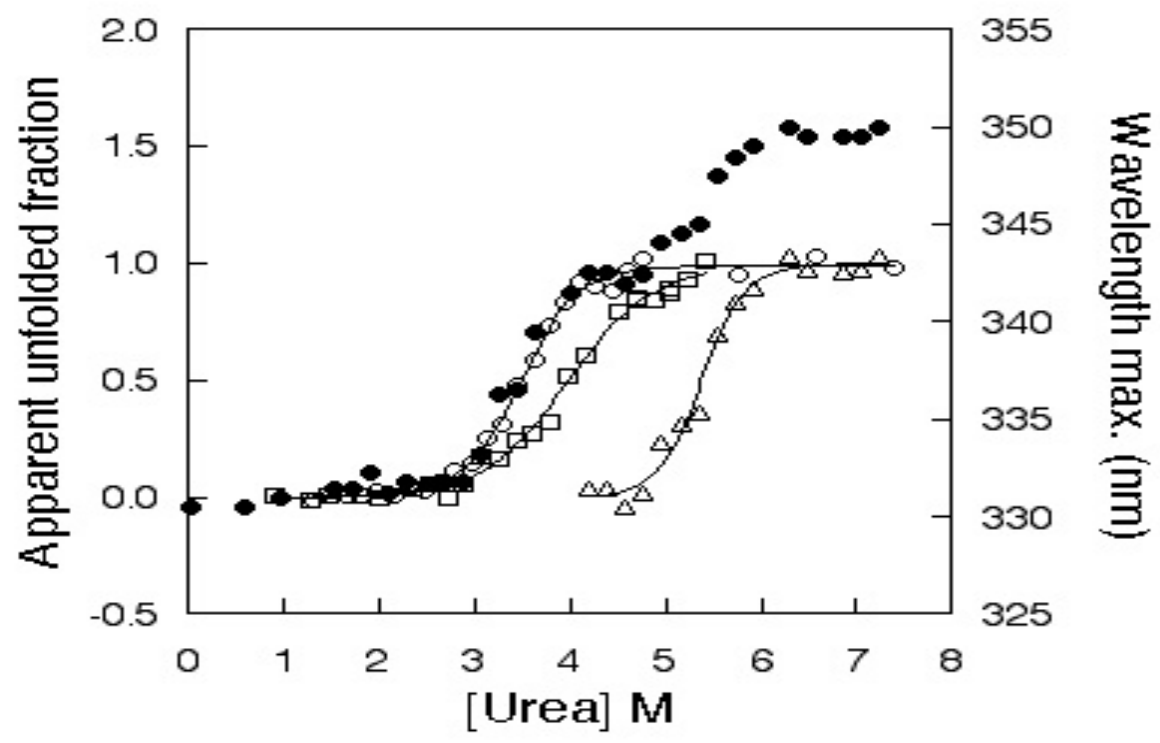

FIGURE 1. Urea denaturation of $\mathrm{scFv}$ at $\mathrm{pH} 7.0$, followed by fluorescence intensity (o), far-UV $\mathrm{CD}(\mathrm{s})$ and wavelength of maximal fluorescence emission $(\bullet)$. The wavelength red-shift at higher urea concentration is additionally represented for better comparison $(\Delta)$.

RESULTS. At neutral $\mathrm{pH}$ and low protein concentration the $\mathrm{scFv}$ is a well-folded monomer and its urea and thermal denaturations are fully reversible. The noncoincidence of the fluorescence and circular dichroism transitions indicates the accumulation of an intermediate $\left(I_{1}\right)$ not previously 
described in scFv molecules. In addition, at higher temperatures or higher urea concentrations, a red-shift in the fluorescence emission maximum reveals a second intermediate $\left(\mathrm{I}_{2}\right)$, similar to one already reported for other scFvs. The equilibrium unfolding of the anti-HBsAg scFv is thus fourstate.

DISCUSSION. Our minimal model for both the urea and the thermal unfolding of the scFv molecule is thus:

$\mathrm{N}<->\mathrm{I}_{1}<\longrightarrow \mathrm{I}_{2}<->\mathrm{U}$

In this model $\mathrm{N}, \mathrm{I}_{2}$ and $\mathrm{U}$ represent the species already characterised by the Plückthun group[3] while $I_{1}$ is a new intermediate. We have globally analysed the urea (and the temperature) unfolding data (as explained in [2]). The global analysis of the thermal unfolding suggests $I_{1}$ displays substantial secondary structure and some well-defined tertiary interactions. Its fluorescence properties are consistent with a disruption of the $\mathrm{V}_{\mathrm{L}} / \mathrm{V}_{\mathrm{H}}$ interface and a compact nonnative conformation of the $\mathrm{V}_{\mathrm{L}}$ domain. The second intermediate probably contains a well-folded $\mathrm{V}_{\mathrm{H}}$ domain and a fully denatured $\mathrm{V}_{\mathrm{L}}$ domain, and unfolds at higher temperature in a noncooperative fashion. Global analysis of the urea unfolding data allows to calculate the $\mathrm{N}-\mathrm{I}_{1}, \mathrm{I}_{1}$ $\mathrm{I}_{2}$, and $\mathrm{I}_{2}-\mathrm{D}$ free energy differences. Although the N-D free energy difference is very large, the N$\mathrm{I}_{1}$ one, representing the 'relevant' conformational stability of the $\mathrm{scFv}$, is small. Stabilising the native state relative to the $I_{1}$ state thus requires an improvement to the 'relevant' conformational stability of this scFv molecule.

\section{REFERENCES}

1. Plückthun, A. (1994) In Immunochemistry. Van Oss, C.J. and van Regenmortel, M.H.V., Eds. Marcel Dekker, New York. pp 201-235.

2. Irún, M.P., Garcia-Mira, M.M., Sanchez-Ruiz, J.M., and Sancho, J. (2001) J. Mol. Biol. 306, 877-888.

3. Wörn, A. and Plückthun, A. (1999) Biochemistry 38, 8739-8750. 